\title{
Insulin Immunization of Nonobese Diabetic Mice Induces a Protective Insulitis Characterized by Diminished Intraislet Interferon- $\gamma$ Transcription
}

\author{
Andrew Muir, ${ }^{\star \ddagger}$ Ammon Peck, ${ }^{\star}$ Michael Clare-Salzler," Yao-Hua Song,, Janet Cornelius, ${ }^{\star}$ Roberto Luchetta, \\ Jeffrey Krischer, $\$$ and Noel Maclaren* \\ ${ }^{*}$ Divisions of Clinical Chemistry and Immunology, Department of Pathology and Laboratory Medicine, and ${ }^{\ddagger}$ Department of Pediatrics, \\ University of Florida, College of Medicine, Gainesville, Florida 32610; and ${ }^{\S}$ University of South Florida, H. Lee Moffitt Cancer Center, \\ Tampa, Florida 32612
}

\begin{abstract}
We reported previously that daily injections of isophane insulin prevented both hyperglycemia and insulitis in nonobese diabetic (NOD) mice (Atkinson, M., N. Maclaren; and R. Luchetta. 1990. Diabetes. 39:933-937). The possible mechanisms responsible include reduced immunogenicity of pancreatic $\beta$-cells from " $\beta$-cell rest" and induced active immunoregulation to insulin (Aaen, K., J. Rygaard, K. Josefsen, H. Petersen, C. H. Brogren, T. Horn, and $K$. Buschard. 1990. Diabetes. 39:697-701). We report here that intermittent immunizations with insulin or its metabolically inactive B-chain in incomplete Freund's adjuvant also prevent diabetes in NOD mice, whereas immunizations with A-chain insulin or with BSA do not. Adoptive transfer of splenocytes from B-chain insulin-immunized mice prevented diabetes in recipients co-infused with diabetogenic spleen cells, an effect that was abolished by prior in vivo elimination of either CD4+ or CD8 + cells. Insulin immunization did not reduce the extent of intraislet inflammation (insulitis); however, it did abolish expression of IFN- $\gamma$ mRNA within the insulitis lesions. Immunizations with insulin thus induce an active suppressive response to determinants on the B-chain that converts the insulitis lesion from one that is destructive to one that is protective. ( $J$. Clin. Invest. 1995. 95:628-634.) Key words: diabetes - immunoregulation - B-chain - adjuvant • therapy
\end{abstract}

\section{Introduction}

Nonobese diabetic (NOD) ${ }^{1}$ mice regularly develop infiltrations of their pancreatic Islets of Langerhans by mononuclear leukocytes (insulitis). The lesion often progresses to an autoimmune-

This work was published in abstract form (1993. Diabetes. 42[Suppl. 1]:5a).

Address correspondence to Andrew Muir, M.D., Department of Pathology and Laboratory Medicine, JH Miller Health Center, P.O. Box 100275, University of Florida, Gainesville, FL 32610. Phone: 904-3923741; FAX: 904-392-6249.

Received for publication 10 May 1994 and in revised form 13 October 1994.

1. Abbreviations used in this paper: IFA, incomplete Freund's adjuvant; NOD, nonobese diabetic.

J. Clin. Invest.

(c) The American Society for Clinical Investigation, Inc.

0021-9738/95/02/0628/07 \$2.00

Volume 95, February 1995, 628-634 mediated destruction of insulin secreting $\beta$-cells and insulindependent diabetes, especially in female mice. Although all NOD/Uf mice acquire considerable islet infiltrates, only $30 \%$ of males and $80 \%$ of females actually develop sustained hyperglycemia by 40 wk of age. The insulitis and diabetes can be transferred to irradiated recipients, indicating that an active autoimmune cellular response is involved. Prior eradication of either CD4+ or CD8+ T lymphocytes from the donor splenocytes ablates this ability to transfer diabetes. It has also been reported that immunomodulatory treatments with complete Freund's adjuvant or oral insulin can prevent or delay the onset of hyperglycemia in NOD mice without eliminating islet infiltration $(1-3)$. It has been proposed that such treatments alter the functional phenotypes of intraislet leukocytes, such that the insulitis lesions become "protective" rather than destructive (4). We report here that deliberate immunization of NOD mice to insulin also induces protective insulitis lesions.

Both diabetes and insulitis can be prevented in NOD mice (5), BB rats (6), and perhaps even in humans (7) by daily prophylactic injections of insulin. An hypothesis of " $\beta$-cell rest"' has been proposed to explain this protection, whereby the pancreatic $\beta$-cells enter a "quiescent" state in which expression of cellular autoantigens is reduced $(8,9)$. Daily administrations of insulin to diabetic patients, however, is known to induce an active immune response characterized by insulin antibodies. We have therefore investigated whether altered immunity to insulin in NOD mice could have a role in the antidiabetic effect of prophylactic insulin therapy. Our studies indicate that an active immunization of NOD mice to an epitope on the B-chain of insulin can prevent diabetes, probably by stimulating an active immunoregulatory response that inhibits intraislet CD8+ cytotoxic T-lymphocyte effector functions.

\section{Methods}

Immunizations of insulin and its B-chain. Six units $(\sim 220 \mu \mathrm{g})$ of purified porcine isophane insulin (Novo Nordisk, Copenhagen, Denmark) in incomplete Freund's adjuvant (IFA) (GIBCO, Grand Island, NY) were administered subcutaneously in the inguinal, axillary, and dorsal neck regions of weanling NOD mice $(n=12)$. Littermate controls received commercial hormone-free isophane insulin diluent (Novo) in IFA $(n=10)$. In a second study, immunizations with equivalent doses of human recombinant insulin were performed $(n=13)$, whereas littermate controls received injections of insulin diluent $(n=12)$ or equimolar amounts of either human recombinant insulin A-chain (105 $\mu \mathrm{g}, n=12$ ) or B-chain ( $140 \mu \mathrm{g}, n=13$ ) in IFA (the insulins used were kindly provided by Dr. R. Chance, Eli Lilly, Indianapolis, IN). The immunizing treatments began at $4 \mathrm{wk}$ of age with subsequent injections given at ages 12,16, and $22 \mathrm{wk}$ in the first study and at 12,20 , and $28 \mathrm{wk}$ in the second study. Blood glucose levels were determined with Chemstrips bG and diabetes was diagnosed when hyperglycemia of over $240 \mathrm{mg} / \mathrm{dl}$ was found. 
Humoral and cellular responses to immunization. Insulin binding by serum antibodies was determined with a liquid-phase competitive radiobinding assay as previously described $(10)$. Splenocyte proliferations were assessed by tritiated thymidine incorporation $(1 \mu \mathrm{Ci} /$ well $)$ during the last $16 \mathrm{~h}$ of an 88-h incubation. Groups of three mice, immunized at 4 and $8 \mathrm{wk}$, had their spleen cells harvested at $9 \mathrm{wk}$. Using flat-bottomed 96-well plates, $5 \times 10^{5}$ cells/well were incubated in triplicate with test antigens in Click's media (Eagle High Amino Acid) supplemented with $0.5 \%$ normal mouse serum (11). The cells were then harvested and the radioactive uptakes were measured using an automated apparatus (Matrix 96, Packard, Meridan, CT). All proliferation studies were performed on at least three separate occasions.

Intravenous splenocyte cotransfer studies. Weanling female mice were left untreated or were immunized at 4 and $8 \mathrm{wk}$ of age with IFA emulsions of either B-chain insulin, A-chain insulin, or diluent. At 10 wk of age, $20 \times 10^{6}$ of their splenocytes were mixed in equal proportion with splenocytes pooled from acutely diabetic codonors and then injected intravenously to irradiated ( $700 \mathrm{rad}$ ) naive male littermates of the immunized codonor mice. Fifteen recipients were co-infused with mixtures containing splenocytes removed after immunizations with Bchain insulin, whereas another 14 recipients received control mixtures of splenocytes (untreated, $n=3$; diluent treated, $n=8$; A-chain insulin treated, $n=3$ ).

In vivo depletion of $\mathrm{CD4}+$ and $C D 8+$ lymphocytes. Synergistic depleting monoclonal antibodies against CD4+ (YTS 191.1 and YTA 3.1.2) and CD8+ (YTS 169.4 and YTS 156.7) T lymphocytes were kindly provided by Dr. Anne Cooke (Cambridge University, UK). Control mice received injections of either PBS or an irrelevant IgG monoclonal antibody against influenza A nucleoprotein (kindly provided by Dr. Parker Small, University of Florida, Gainesville). Starting 1 wk after completing a two-dose immunizing course of B-chain insulin at 4 and 8 wk of age, one intravenous dose followed by two intraperitoneal monoclonal antibody or control treatments were administered. These were given 7, 5, and $3 \mathrm{~d}$ before the animals were killed. The depleting capacity of these hybridomas have been repeatedly demonstrated in the laboratory of Herman Waldmann at Cambridge, U.K., both in vitro, by $\mathrm{Cr}^{51}$ release assays, and in vivo, by staining of peripheral blood or lymph node cells with target cell-specific first antibodies and biotinylated second antibody against rat IgG and rat $\kappa$ light chains. In antibodytreated thymectomized mice, no regeneration of either of the targeted lymphocytes subsets was observed, whereas CD4 + T-lymphocyte recovery after a single dose of YTS 191.1 in euthymic mice was not detectable for up to $10 \mathrm{~d}$ after the antibody treatment. In vivo antiCD4 antibody treatments also reduced primary and secondary humoral responses to sheep erythrocytes and inhibited mitogen-stimulated IL2 production. Combined anti-CD4 and anti-CD8 treatment conferred tolerance to allogeneic skin grafts that was more long-lived than that induced by either antibody given alone (12-14).

We performed flow cytometric analyses of splenocytes from treated or control mice on a FACScan (Becton-Dickinson, San Jose, CA) after staining with GK1.5 (anti-CD4) and clone 53-6.7 (anti-CD8) antibodies (Pharmingen, San Diego, CA). Using splenocytes from B-chain immunized donors whose $T$ cells were depleted before they were killed, adoptive cotransfers were repeated. Before transfer, six donors received treatments with anti-CD4 antibodies, eight animals were treated with anti-CD8 antibodies, and seven received injections of either PBS ( $n$ $=3$ ) or the irrelevant IgG monoclonal antibody $(n=4)$.

Histology. Female NOD mice immunized to either A-chain $(n=9)$ or B-chain $(n=7)$ insulin or treated with insulin diluent in IFA ( $n$ $=9$ ) at 4 and 8 wk of age underwent pancreatic histological studies. They were killed at $10 \mathrm{wk}$ of age (the age of established insulitis but before their onsets of diabetes), and their pancreases were removed, fixed in $10 \%$ formalin, and stained with hematoxylin and eosin for light microscopic examinations. The slides were coded and an insulitis score was determined by three independent examiners. The results were pooled and averaged before the codes were broken. The degree of insulitis was scored from 0 to 3 using a previously described dual scale that assessed both the severity of immune infiltration and the cytoarchitectural disruption (5).

Cytokine production within infiltrated islets. At 4 and $8 \mathrm{wk}$ of age, groups of three to four mice each received multiple subcutaneous injections of emulsions of IFA containing either insulin diluent, A-chain, or B-chain. The studies were also controlled with groups of untreated littermates. At 10 wk of age, islets from nondiabetic mice were handpicked after pancreatic mincing and collagenase/DNAse digestion. The islets were dispersed with Trypsin at $37^{\circ} \mathrm{C}$ and the mRNA was extracted using the Micro-Fast Track mRNA Isolation Kit (InVitrogen, San Diego, CA). Cytokine-specific primers were designed as outlined previously (15). After completing RT-PCR and agarose electrophoresis, the DNA was Southern blotted to nylon membranes (Boehringer-Mannheim, Indianapolis, IN) in $0.4 \mathrm{~N} \mathrm{NaOH}$ and their identities confirmed using digoxigenin-labeled cytokine-specific internal probes and the $\mathrm{Ge}-$ nius detection system (Boehringer-Mannheim). The number of islets from which message was extracted was considered as the standard for comparison between groups. The studies were performed in triplicate. The yield of DNA product using this PCR protocol has a log-linear relationship with the concentration of added template (IFN- $\gamma$ cDNA from Clontech, Palo Alto, CA) over at least six orders of magnitude $(50 \mathrm{aM}-50 \mathrm{nM})$. The profiles reported below were readily reproducible in replicate experiments.

Statistics. The method of Kaplan and Meier (16) was used to construct life tables and the logrank Chi-square statistic was used to compare them (17). A Student's $t$ test or one-way ANOVA was used to compare means. $P$ values are two sided.

\section{Results}

Immunizations of insulin and its $B$-chain protect NOD mice from diabetes. Because the two immunization protocols yielded similar results, only the combined data are presented here. As shown in Fig. 1, insulin immunizations dramatically lowered the incidence of diabetes over the 40-wk study period. The protection against diabetes was reproduced by immunizing with B-chain insulin but, importantly, not by immunizing with Achain insulin or with BSA as controls (latter data not presented).

The insulin immunizations stimulated active antigen-specific responses in both the humoral and the cellular arms of the immune system as expected, documenting that immunizations had not induced antigen-specific anergy. Fig. $2 A$ presents the frequency of anti-insulin antibody-positive mice after immunization. In all of eight insulin-immunized mice, specific antiinsulin antibodies were detected at levels that were $\geq 10$-fold above those typical of insulin autoantibodies in untreated NOD mice in our radiobinding assay. Similarly, increases of insulin binding antibodies were also observed in sera from mice immunized against either A- or B-chain insulin. Antigen-specific proliferative responses, although modest, were also consistently stimulated as demonstrated in Fig. $2 B$.

Protection from diabetes can be adoptively transferred to naive recipients. To confirm the active immune basis of the therapeutic effect of B-chain insulin immunizations, 10-wk-old male irradiated recipient NOD mice were injected with splenocytes from immunized female littermates together with an equal number of splenocytes harvested from female diabetic codonors. Life table analysis revealed a significant delay in the onset of diabetes among the mice that received infusions of splenocytes from B-chain insulin-immunized donors $(P$ $<0.007$, Fig. 3) Among recipients of splenocytes from the untreated $(n=3)$, A-chain-immunized $(n=3)$, and diluentimmunized control groups $(n=8), 11$ of $14(79 \%)$ became 


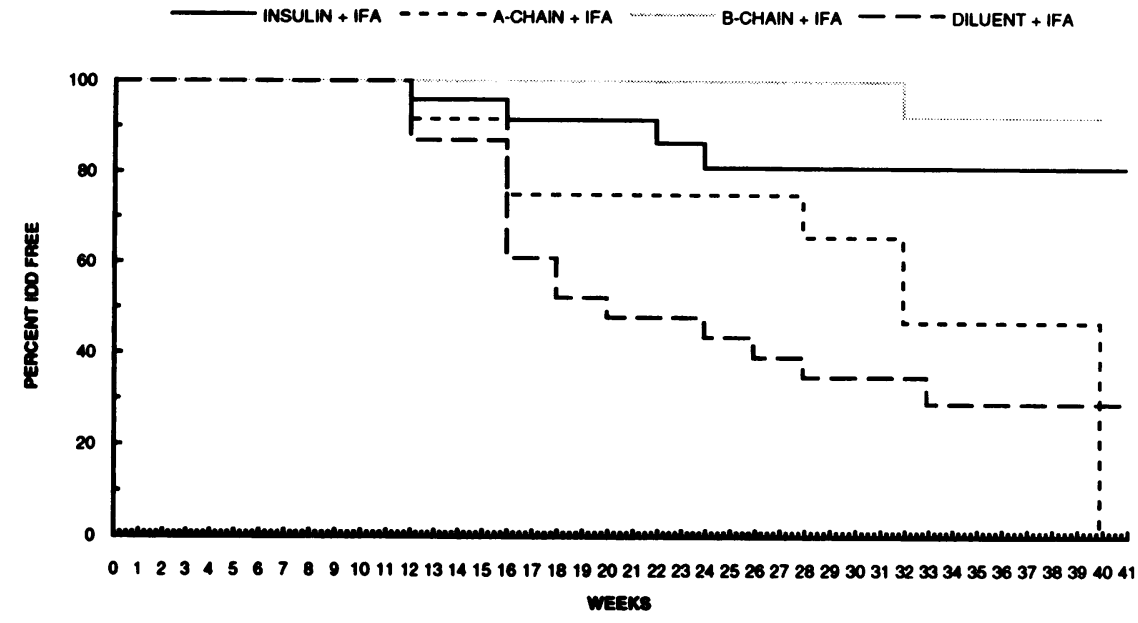

Figure 1. Subcutaneous insulin peptides in IFA in NOD mice. The survival curve shows the probability of remaining nondiabetic among female NOD mice who received IFA suspensions containing either insulin diluent, isophane insulin, insulin A-chain, or insulin B-chain. Immunization with insulin B-chain provided protection equal to that conferred by intact insulin diabetic within 3 wk of cell transfer. In contrast, diabetes occurred in only 3 of $15(20 \%)$ recipients of splenocytes from Bchain-immunized donors over the same time frame.

In B-chain insulin-immunized mice that received an in vivo course of lymphocyte-depleting antibodies before they were killed, flow cytometric analysis of splenocytes suggested virtually complete depletion of the respective T cell subsets, 3 full $\mathrm{d}$ after the depleting antibody course had been completed, supporting that specific $\mathrm{T}$ cell depletions had been affected. Both the anti-CD4 and anti-CD8 treatments reduced their respective target cell markers by $96 \%$ compared with PBS-injected control mice (Fig. 4A). These profiles lasted for days after completing the antibody course, supporting that specific $\mathrm{T}$ cell depletions had been affected. Depletion of either CD4+ or CD8+ T lymphocytes before transfer abrogated the ability of B-chain-immunized splenocytes to prevent the transfer of diabetes ( $P$ $<0.01) .3 \mathrm{wk}$ after the splenocyte transfer, five of six recipients depleted of $\mathrm{CD} 4+\mathrm{T}$ cells and four of five recipients depleted of CD8 + $\mathrm{T}$ cells became hyperglycemic (Fig. $4 B$ ). These experiments suggest that $B$-chain insulin immunizations inhibit islet destruction by promoting an active antigen-specific immunoregulatory lymphocyte network with suppression of islet cell autoimmunity.

Histological insulitis grade is not decreased by B-chain insulin immunization. Despite the lower frequency of diabetes seen in mice with B-chain insulin immunization, histologic studies revealed that the extent of mononuclear leukocyte infiltration of their islets was not reduced by the treatments. Using an infiltration scale of 0-3 (1), the mean and SE insulitis scores in pancreases of 10-wk-old mice immunized at $4 \mathrm{wk}$ of age were $0.9 \pm 0.2,1.3 \pm 0.3$, and $1.5 \pm 0.2$ for diluent ( $n=9$ mice $)$, A-chain ( $n=9$ mice), and B-chain ( $n=7$ mice) treated groups, respectively $(P=0.3)$. The time chosen reflected an early phase of the established lesion. Further, flow cytometric analyses revealed no significant differences in the proportions of $\mathrm{CD} 3+, \mathrm{CD} 4+, \mathrm{CD} 8+$, or I-A+ cells in dispersed islet cell preparations from treated and control mice (data not presented).

Immunizations alter cytokine production within infiltrated islets. To assess whether functional differences existed between the islet-infiltrating immune cells of treated and control mice, cytokine mRNA profiles were examined by RT-PCR analyses (15). The panel of cytokine-specific primers we used included IL- $1 \beta$, IL-2, IL-4, IL-10, TGF- $\beta_{3}$, and IFN- $\gamma$. The salient re- sults are presented in Fig. 5. High levels of IL-10 and TGF$\beta_{3}$ were observed in untreated mice but were not consistently increased further by insulin immunizations. Increased levels of IL-4 mRNA were observed after immunizations with IFA alone, an effect that was not seen after specific immunizations to either of the insulin peptide chains. Immunizations with either A-chain or B-chain increased intraislet levels of IL- $\beta$ and IL-2 mRNA compared with controls. However, the most notable change that was specific to islet infiltrates of the highly protected B-chain insulin-immunized mice was a consistently reduced level of IFN- $\gamma$ mRNA.

As demonstrated by in vivo depletion of CD4+ or CD8+ cells from control unimmunized NOD mice, CD8+ cells are the predominant source of intraislet IFN- $\gamma$. Cytokine mRNA levels were, however, enhanced when both $\mathrm{T}$ cell subsets remained (Fig. 6). In contrast, depletion of CD4+ cells in B-chain insulin-immunized mice reduced the levels of IFN- $\gamma$ below the limits of detection, documenting that a reduction in CD8 $+\mathrm{T}$ lymphocyte transcription of IFN- $\gamma$ had occurred after immunizations with B-chain insulin (Fig. 6).

\section{Discussion}

An increasing number of self-antigens targeted in autoimmune disease states have been identified at the molecular level, permitting autoantigen-based immunotherapies to become a major research focus (18-24). To date, these antigen-based therapies have attempted to restore immunological tolerance or to otherwise induce unresponsiveness to self-antigens implicated as important in disease pathogenesis. The ability of immunization to insulin or its B-chain to prevent IDD in an antigen-specific fashion is therefore novel, because it depends on an active immune sensitization to the autoantigen and not anergy induction. Antigen specificity for the effect was demonstrated by the persistence of diabetes in NOD mice immunized with either Achain insulin or BSA in IFA and protection when immunization to B-chain was used. The induction of both humoral and in vitro cellular responses specific to the immunizing antigen documented that an active immunoregulatory process was involved and specifically ruled out the possibility that antigen-mediated immunological anergy had been induced. This hypothesis was confirmed in the adoptive cotransfer experiments, through which diabetes was prevented in naive irradiated mice receiving 
A

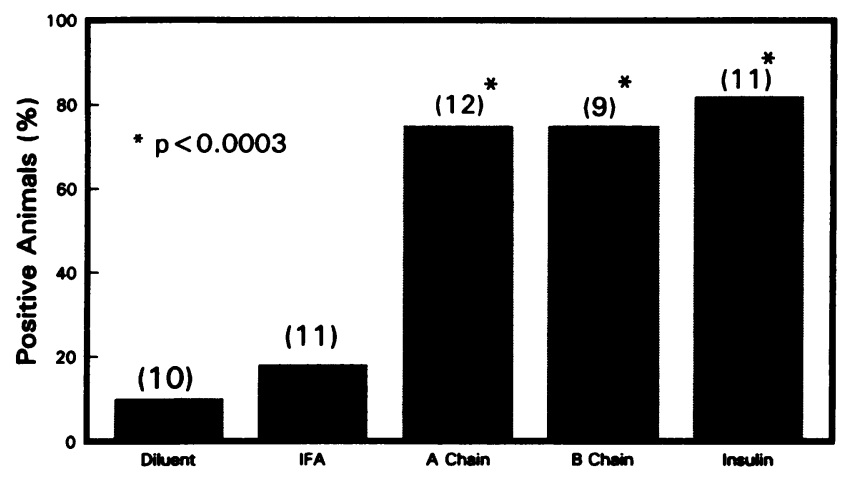

B

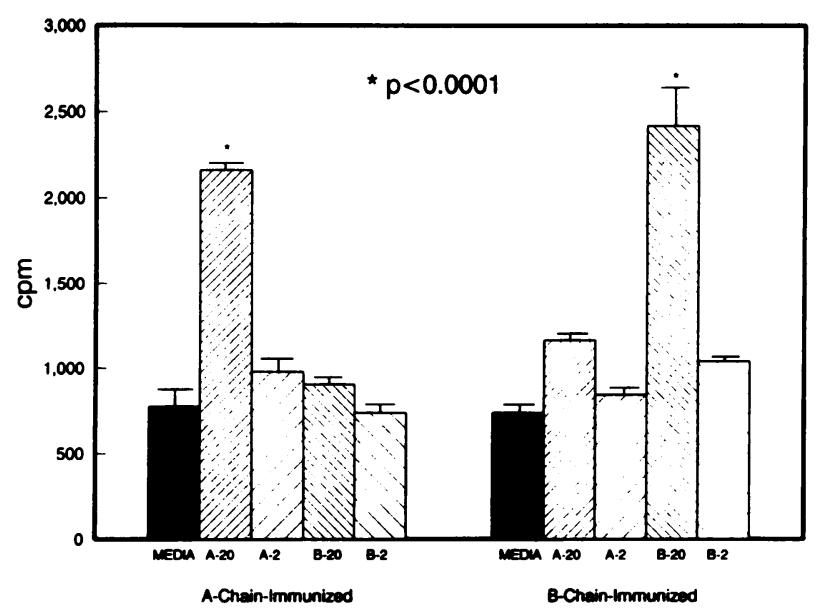

Figure 2. Antigen-specific humoral and cellular responses to immunization. $(A)$ Serum IAA levels were measured in samples that were obtained before the second immunization at $12 \mathrm{wk}$ of age. The number of mice tested at each time is presented in parentheses above the bar. A low frequency of spontaneously appearing insulin autoantibodies was observed in diluent and diluent + IFA injected mice. Those that were immunized to insulin or its component peptides had high frequencies and absolute levels of anti-insulin antibodies. $(B)$ In vitro proliferative responses of spleen cells to 2 and $20 \mu \mathrm{g} / \mathrm{ml}$ of A-chain and B-chain insulins are shown. 9-wk-old mice were killed after they had received immunizations of A- or B-chain insulin in IFA at 4 and $8 w k$. Error bars represent $1 \mathrm{SD}$ of the triplicate mean. Antigen-specific responses were observed that were dose dependent. Similar results were obtained in four separate experiments.

infusions of splenocytes from diabetic donors but only when cotransfers of splenocytes from B-chain insulin-immunized littermates were simultaneously performed. The requirement for both CD4+ and CD8 + T lymphocytes to successfully transfer the antidiabetic effect of B-chain insulin immunization suggests that the treatment acts by inducing a complex lymphocyte immunoregulatory network that has protective properties $(25,26)$. Both CD4+ $\mathrm{Th}_{1}$ and noncytotoxic CD8 + T-lymphocyte clones have been isolated from NOD mouse islets that can prevent diabetes when injected back into susceptible NOD recipients $(27,28)$. Furthermore, similar cotransfers of spleen cells from diabetic and young nondiabetic donors result in protection from diabetes in the recipients (29).

Immunization to A-chain insulin induced many of the same immunologic responses observed after B-chain insulin treat- ments, yet it did not protect against diabetes. Specific humoral and cellular responses were induced and there were parallel changes in intraislet production of IL-1, IL-2, and IL-4 using immunizations with either chain of insulin. Whereas these immunization-induced responses may in fact represent irrelevant changes, the protective CD4+/CD8 $+\mathrm{T}$ cell-dependent immunoregulatory network induced by B-chain insulin immunizations was associated with reduced intraislet CD8+ lymphocyte production of IFN- $\gamma$. Reductions of IFN- $\gamma$ mRNA levels in the CD4+ T-lymphocyte population may also have been induced by immunization with insulin B-chain, but this remains unproven and is a focus for further study.

Insulin is one of many $\beta$-cell autoantigens targeted by the autoimmune response that leads to diabetes in NOD mice, but autoimmune responses against the hormone have not been considered necessary for the induction of diabetes (30). The near complete protection from disease after therapeutic immunization with B-chain insulin is therefore consistent with the possibility that "bystander immunosuppression"' has been induced. This term describes the antigen specific immunoregulatory cell release of cytokines by activated $T$ cells, upon reencounter with the inciting antigen. The paracrine actions of such cells then down-regulate other autoreactive activated immune cells in the islet inflammatory lesion, irrespective of their cognate antigens $(31-33)$. The effect has been studied most in experimental allergic encephalomyelitis, induced in rodents by immunizations with myelin basic protein. The release of TGF- $\beta$ and/ or IL-4 from myelin basic protein-specific suppressor cells is believed to ameliorate the central nervous system disease of experimental allergic encephalomyelitis by inhibiting the functions of proinflammatory cells. IL-10 is another regulatory cytokine that could have such actions; however, both beneficial and detrimental effects of IL-10 on islet viability have been described in NOD mice $(34,35)$. The intraislet cytokine profiles induced by B-chain insulin immunization, however, did not demonstrate elevations of any of these cytokines, which were, however, abundant both before and after the immunizations.

Reductions of intraislet IFN- $\gamma$ mRNA were repeatedly demonstrated in animals who received B-chain insulin immunizations but were not observed in control mice receiving any of the nonprotective therapies. Recently, infiltrating CD8 + T lymphocytes have been reported to be the predominant source of IFN- $\gamma$ in NOD mouse islets (15). In agreement with this, we found that in vivo antibody treatments that depleted CD8 $+\mathrm{T}$ cells of normal NOD mice reduced intraislet IFN- $\gamma$ mRNA more than did depletions of CD4+ T cells. Thus there was considerable transcription of IFN $-\gamma$ mRNA from $\mathrm{CD} 8+\mathrm{T}$ cells in normal NOD mice. In contrast, islets from B-chain insulinimmunized mice demonstrated marked reductions of IFN- $\gamma$ transcripts and their virtual elimination was observed after subsequent anti-CD4 treatments in vivo, whereas the respective effects from anti-CD8+ treatment were much less obvious. These results indicate that B-chain insulin immunizations reduced IFN $-\gamma$ production at least by $\mathrm{CD} 8+\mathrm{T}$ cells. We suspect that the immunization-induced process that protects islets is probably complex, and one that will require further study to unravel.

Reduction of intraislet IFN- $\gamma$ may spare $\beta$-cells directly because the cytokine itself appears to have important effector actions in islet cell autoimmunity. In combination with other cytokines such as TNF- $\alpha$ or IL-1, IFN- $\gamma$ has been reported to be directly cytotoxic to islet $\beta$-cells $(36-38)$. Furthermore, 


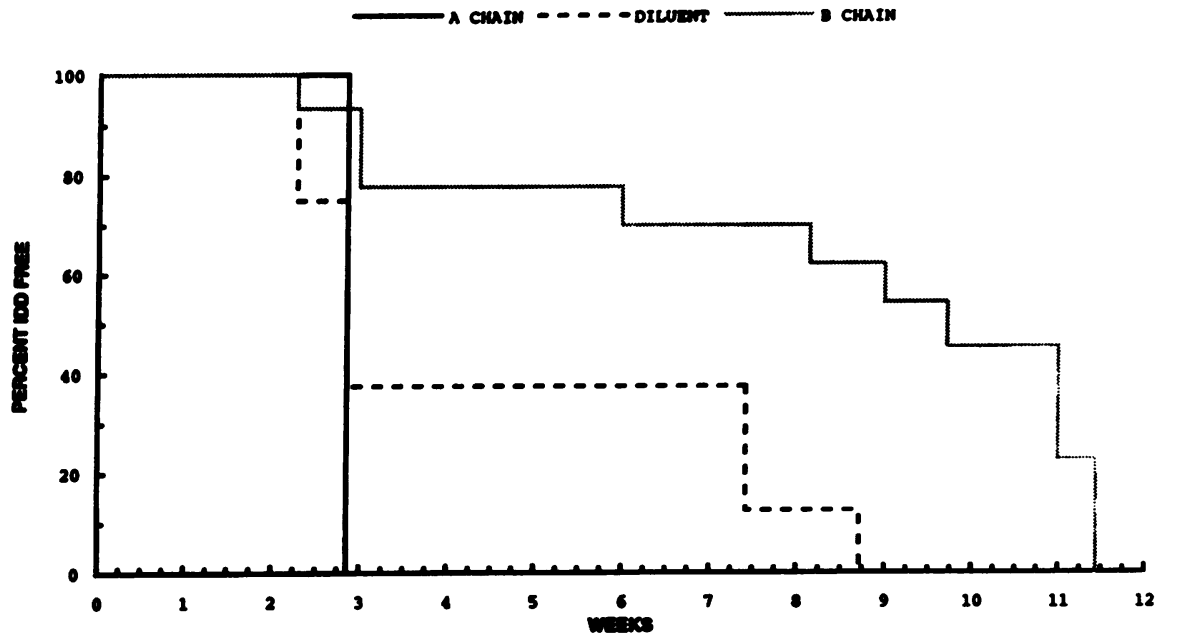

Figure 3. Protection from diabetes can be adoptively transferred to naive recipients. Weanling female mice were left untreated or were immunized at 4 and 8 wk of age with IFA emulsions of either B-chain insulin, Achain insulin, or diluent. At 10 wk of age, their splenocytes were mixed in equal proportion with splenocytes pooled from acutely diabetic codonors and then injected intravenously to irradiated naive male littermates of the immunized codonors (untreated, $n=3$; diluent treated, $n=8$; A chain treated, $n=3$; B chain treated, $n=15$ ). Protection from the adoptive transfer of diabetes was conferred best by the splenocytes of $B$ chaintreated codonors $(P<0.007)$.

insulitis and diabetes have been demonstrated in mice selectively expressing intraislet IFN- $\gamma$ through a transgene linked to an insulin gene promoter (39). Conversely, anti-IFN- $\gamma$ antibody treatments have been shown to improve disease outcomes $(35,40)$. That immunizations by B-chain insulin could so profoundly lower intraislet IFN- $\gamma$ may well account for the benefit induced; however, the intermediate steps that promote this result need further study.

Our studies suggest that the role of autoimmunity to insulin in $\beta$ cell autoimmunity leading to insulin-dependent diabetes should be reconsidered. Insulin is an abundant autoantigen in islets that is specific to $\beta$ cells. A high proportion of islet-

A
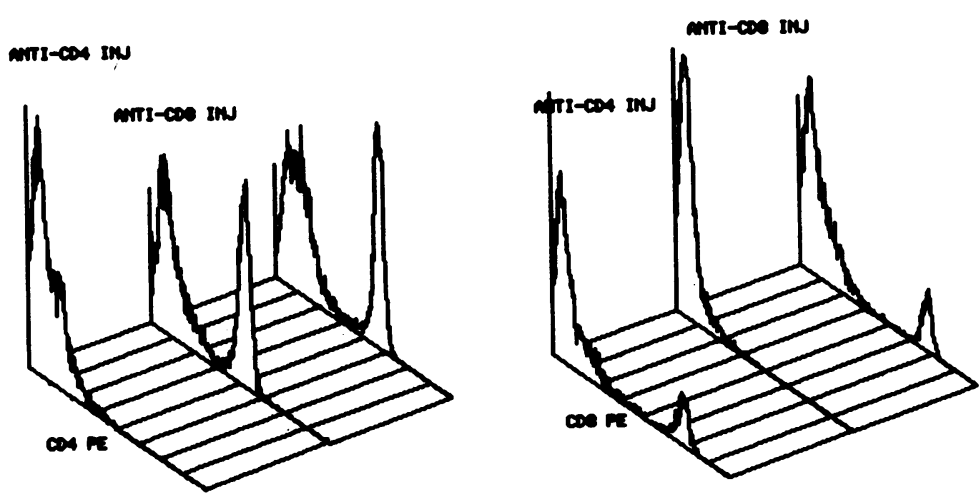

B

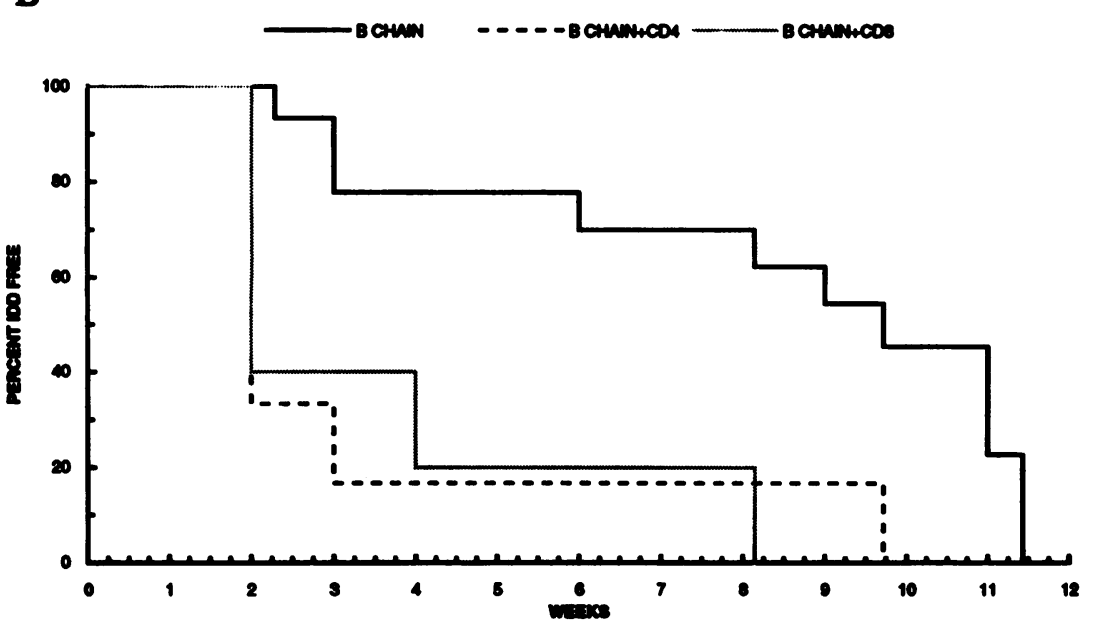

Figure 4. Successful transfer of protection requires both CD4+ and CD8+ T lymphocytes. The B-chain immunization adoptive cotransfer protocol was repeated except that the treated codonors received anti-CD4 or anti-CD8 depleting monoclonal antibodies before they were killed, whereas control mice received injections of either PBS or an anti-influenza A nucleoprotein IgG murine monoclonal (anti-CD4, $n=6$; anti-CD8, $n=6$; control, $n=7$ ). ( $A$ ) Flow cytometric analysis of splenocytes from antibodyor control-treated mice revealed nearly complete depletion by the monoclonal pairs. Staining of spleen cells from mice treated with the monoclonal control antibody are shown on the rightmost axis of each plot. The left plot shows depletion of CD4+ $T$ lymphocytes $(96 \%)$ in anti-CD4-treated mice compared with anti-CD8-treated or control mice. The right plot demonstrates depletion of CD8 $+\mathrm{T}$ lymphocytes $(96 \%)$ in anti-CD8-treated mice but not anti-CD4-treated or control mice. $(B)$ Depletion of either CD4+ (dashed line) or CD8+ (dotted line) lymphocytes allowed successful adoptive transfer of diabetes to B-chain immunized mice, whereas B-chain immunization without lymphocyte depletion delayed the transfer of disease (solid line) $(P<0.01)$. 


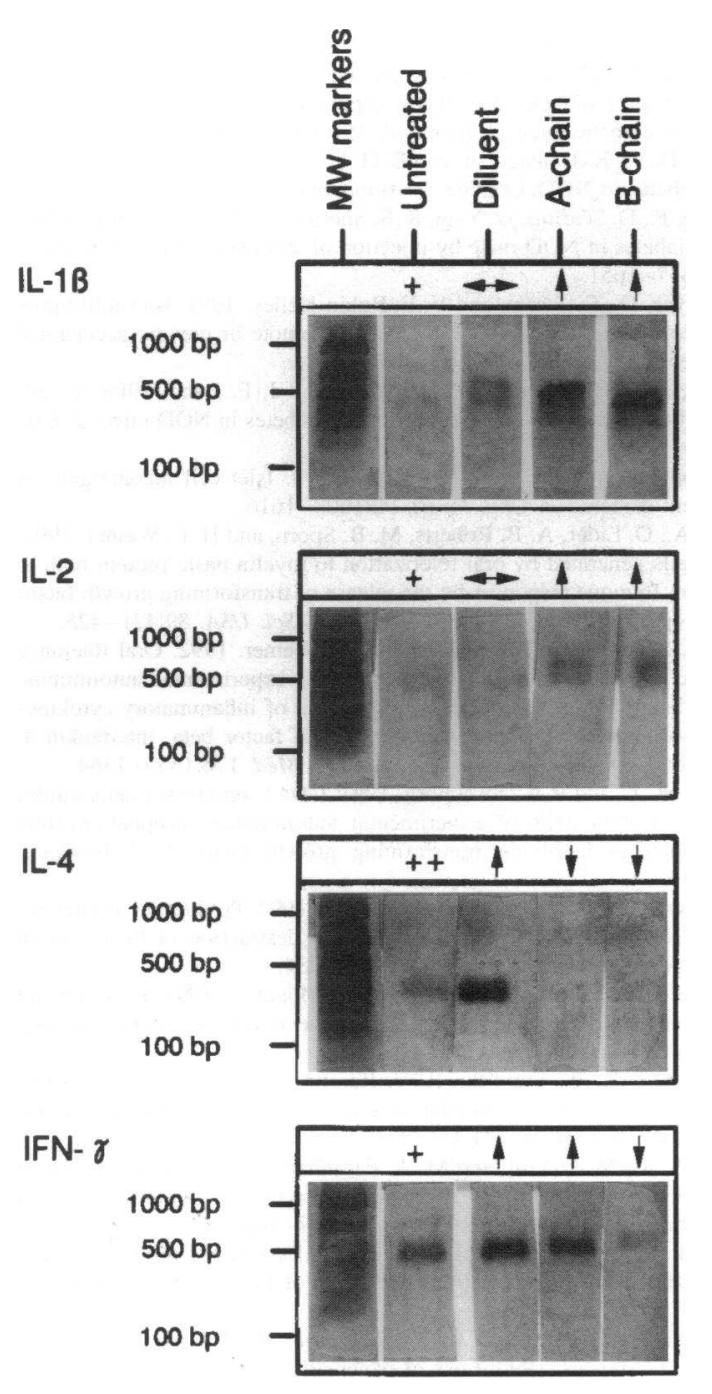

Figure 5. Immunizations alter cytokine production within infiltrated islets. At 4 and $8 \mathrm{wk}$ of age, groups of three to four mice each received multiple subcutaneous injections of emulsions of IFA containing either insulin diluent, A-chain, B-chain, or else were left untreated. At $10 \mathrm{wk}$ of age, the mRNA from single islet cell suspensions was purified from nondiabetic mice. The RT-PCR products were Southern blotted and their identities confirmed using digoxigenin-labeled internal probes. Intraislet IL- $1 \beta$ and IL- 2 mRNAs were increased after either A-chain or B-chain insulin immunizations, whereas the level of IL-4 mRNA was increased only after treatments of diluent + IFA alone. Immunization with either A- or B-chain was associated with diminished levels of IL4 mRNA. Selective depression of IFN- $\gamma$ with respect to levels in untreated mice (as shown with arrows) was observed after B-chain insulin immunization. The blots shown are typical of those seen in three separate experiments.

derived NOD T cell clones are reported to be reactive to epitopes on the B-chain of insulin. Some of these clones actually appear able to mediate diabetes (Wegmann, D., personal communication). Diabetes may eventually arise only after pancreatic $\beta$-cells suffer progressive damage from a cascade of autoimmune responses against multiple autoantigens. Insulin B-chain immunization therapy may inhibit progression of the autoantigen determinant cascade (23).

Although the exact immune mechanism by which insulin

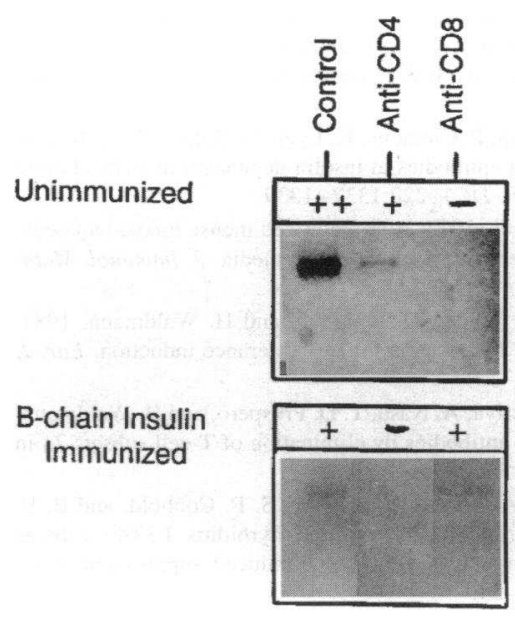

Figure 6. IFN- $\gamma$ mRNA is depleted primarily from CD8+ T lymphocytes. To determine the source of IFN- $\gamma$, female NOD mice were either left untreated or immunized with B-chain insulin in IFA at 4 and $8 \mathrm{wk}$ of age. Both groups were depleted of either their CD4+ or CD8+ T lymphocytes as described. IFN- $\gamma$ transcript levels in unimmunized mice were highest in preparations depleted of their CD4+ but not their $\mathrm{CD} 8+\mathrm{T}$ lymphocytes. Among Bchain insulin-immunized mice, IFN- $\gamma$ mRNA could not be detected in the islet infiltrates of mice depleted of their CD8 + cells. Thus B-chain insulin immunization had eliminated $\mathrm{CD} 8+\mathrm{T}$ lymphocyte production of IFN- $\gamma$.

immunization protects against diabetes remains under investigation, we suggest that immunizations to insulin B-chain stimulates an immunoregulatory network complex that induces a protective immune response, characterized by a reduction of IFN$\gamma$ by intraislet CD8 $+\mathrm{T}$ lymphocytes. This unique approach of therapeutic immunostimulation stands in stark contrast to currently proposed treatments that aim to inhibit autoimmunity through induction of anergy to self-antigens. Further development of this model may well lead to human therapeutic trials for insulin-dependent diabetes if not other autoimmune diseases, especially when investigations focus on peptides that are without metabolic activity.

\section{Acknowledgments}

This work was supported by grants from the National Institutes of Health (RO1 HD19469-09), the Juvenile Diabetes Foundation, International (1929523), the Children's Miracle Network Telethon, and a generous gift from Sidney Kriser.

\section{References}

1. Shehadeh, N., F. Calcinaro, B. J. Bradley, L. Bruchlim, P. Vardi, and K. J. Lafferty. 1994. Effect of adjuvant therapy on development of diabetes in mouse and man. Lancet. 343:706-707.

2. Sadelain, M. W., H. Y. Qin, J. Lauzon, and B. Singh. 1990. Prevention of type I diabetes in NOD mice by adjuvant immunotherapy. Diabetes. 39:583-589.

3. Muir, A., D. Schatz, and N. Maclaren. 1993. Antigen specific immunotherapy. Oral tolerance and subcutaneous immunization in the treatment of insulindependent diabetes. Diabetes Metab. Rev. 9:279-287.

4. Shehadeh, N. N., F. LaRosa, and K. J. Lafferty. 1993. Altered cytokine activity in adjuvant inhibition of autoimmune diabetes. Autoimmunity. 6:291300.

5. Atkinson, M., N. Maclaren, and R. Luchetta. 1990. Insulitis and diabetes in NOD mice reduced by prophylactic insulin therapy. Diabetes. 39:933-937.

6. Gotfredsen, C. F., K. Buschard, and E. K. Frandsen. 1985. Reduction of diabetes incidence of BB Wistar rats by early prophylactic insulin treatment of diabetes-prone animals. Diabetologia. 28:933-935.

7. Keller, R. J., R. A. Jackson, and G. S. Eisenbarth. 1993. Insulin prophylaxis in individuals at high risk for the development of type 1 diabetes mellitus. Lancet. 341:927-928.

8. Aaen, K., J. Rygaard, K. Josefsen, H. Petersen, C. H. Brogren, T. Horn, and K. Buschard. 1990. Dependence of antigen expression on functional state of beta-cells. Diabetes. 39:697-701. 
9. Björk, E., O. Kämpe, J. Grawe, A. Hallberg, I. Norheim, and F. A. Karlsson. 1993. Modulation of beta-cell activity and its influence on islet cell antibody (ICA) and islet cell surface antibody (ICSA) reactivity. Autoimmunity. 16:181188.

10. Palmer, J. P., C. M. Asplin, P. Clemons, K. Lyen, O. Tatpati, P. K. Raghu, and T. L. Paquetto. 1983. Insulin antibodies in insulin-dependent diabetics before insulin treatment. Science (Wash. DC). 222:1337-1339.

11. Peck, A. B., and F. H. Bach. 1973. A miniaturized mouse mixed leukocyte culture in serum-free and mouse serum supplemented media. J. Immunol. Meth ods. 3:147-164.

12. Qin, S., S. Cobbold, H. Tighe, R. Benjamin, and H. Waldmann. 1987. CD4 monoclonal antibody pairs for suppression and tolerance induction. Eur. J. Immunol. 17:1159-1165.

13. Cobbold, S. P., A. Jayasuriya, A. Nash, T. D. Prospero, and H. Waldmann 1984. Therapy with monoclonal antibodies by elimination of T-cell subsets 24 in vivo. Nature (Lond.). 312:548-551.

14. Kong, Y.-C. M., A. G. Alvaro, H. Waldmann, S. P. Cobbold, and B. E. Fuller. 1989. Resistance to experimental autoimmune thyroiditis: L3T4+ cells as mediators of both thyroglobulin-activated and TSH-induced suppression. Clin. Immunol. Immunopathol. 51:38-54.

15. Anderson, J. T., J. G. Cornelius, A. J. Jarpe, W. E. Winter, and A. B. Peck. 1993. Insulin-dependent diabetes in the NOD mouse model. II. $\beta$ cell destruction in autoimmune diabetes is a $\mathrm{T}_{\mathrm{H} 2}$ and not a $\mathrm{T}_{\mathrm{H} 1}$ event. Autoimmunity. 15:113-122.

16. Kaplan, E. L., and P. Meier. 1958. Nonparametric estimation from incomplete observations. J. Am. Stat. Assoc. 53:457-481.

17. Mantel, N. 1988. Evaluation of survival data and two new rank order statistics arising in its consideration. Cancer Chemother. Rep. 50:163-170.

18. Lider, O., L. M. B. Santos, C. S. Y. Lee, P. J. Higgins, and H. L. Weiner. 1989. Suppression of experimental autoimmune encephalomyelitis by oral administration of myelin basic protein. II. Suppression of disease and in vitro immune responses is mediated by antigen specific CD8 $+\mathrm{T}$ lymphocytes. $J$. Immunol. 142:748-752.

19. Zhang, Z. J., S. Shoelson, A. Miller, and H. L. Weiner. 1992. Insulitis is suppressed in NOD mice by oral administration of insulin peptides and glucagon. FASEB (Fed. Am. Soc. Exp. Biol.) J. 6:1693.

20. Elias, D., and I. R. Cohen. 1994. Peptide therapy for diabetes in NOD mice. Lancet. 343:704-706.

21. Adorini, L., V. Barnaba, C. Bona, F. Celada, A. Lanzavecchia, E. Sercarz, N. Suciu Foca, and H. Wekerle. 1990. New perspectives on immunointervention in autoimmune diseases [news]. Immunol. Today. 11:383-386.

22. Steinman, L. 1990. Development of antigen-specific therapies in autoimmune disease. Mol. Biol. Med. 7:333-339.

23. Kaufman, D. L., M. Clare-Salzler, J. Tian, T. Forsthuber, G. S. P. Ting, P. Robinson, M. A. Atkinson, E. E. Sercarz, A. J. Tobin, and P. V. Lehmann. 1993. Spontaneous loss of T cell self tolerance to glutamate decarboxylase is a key event in the pathogenesis of murine insulin-dependent diabetes. Nature (Lond.). 366:69-71.

24. Tisch, R., X.-D. Yang, S. M. Singer, R. S. Liblau, L. Fugger, and H. O.
McDevitt. 1993. Immune response to glutamic acid decarboxylase correlates with insulitis in non-obese diabetic mice. Nature (Lond.). 366:72-75.

25. Kawamura, T., M. Nagata, T. Utsugi, and J.-W. Yoon. 1993. Prevention of autoimmune type 1 diabetes by CD4+ suppressor $\mathrm{T}$ cells in superantigentreated non-obese diabetic mice. J. Immunol. 151:4362-4370.

26. Serreze, D. V., K. Hamaguchi, and E. H. Leiter. 1989. Immunostimulation circumvents diabetes in NOD/Lt mice. J. Autoimmun. 2:759-776.

27. Reich, E. P., D. Scaringe, J. Yagi, R. S. Sherwin, and C. A. Janeway. 1989. Prevention of diabetes in NOD mice by injection of autoreactive T-lymphocytes. Diabetes. 38:1647-1651.

28. Pankewycz, O., O. Strom, and V. E. Rubin-Kelley. 1991. Islet-infiltrating $\mathrm{T}$ cell clones from non-obese diabetic mice that promote or prevent accelerated onset of diabetes. Eur. J. Immunol. 21:873-879.

29. Boitard, C., R. Yasunami, M. Dardeene, and J. F. Bach. 1989. T cellmediated inhibition of the transfer of autoimmune diabetes in NOD mice. J. Exp. Med. 169:1669-1680.

30. Atkinson, M. A and N. K. Maclaren. 1993. Islet cell autoantigens in insulin-dependent diabetes. J. Clin. Invest. 92:1608-1616.

31. Miller, A., O. Lider, A. B. Roberts, M. B. Sporn, and H. L. Weiner. 1992 Suppressor $\mathrm{T}$ cells generated by oral tolerization to myelin basic protein both in vitro and in vivo. Immune responses by the release of transforming growth factor $\beta$ after antigen-specific triggering. Proc. Natl. Acad. Sci. USA. 89:421-425.

32. Khoury, S. J., W. W. Hancock, and H. L. Weiner. 1992. Oral tolerance to myelin basic protein and natural recovery from experimental autoimmune encephalomyletis are associated with downregulation of inflammatory cytokines and differential upregulation of transforming growth factor beta, interleukin 4 , and prostaglandin E expression in the brain. J. Exp. Med. 176:1355-1364.

33. Karpus, W. J., and R. L. Swanborg. 1991. CD4+ suppressor cells inhibit the function of effector cells of experimental autoimmune encephalomyelitis through a mechanism involving transforming growth factor- $\beta$. J. Immunol. 146:1163-1168.

34. Wogensen, L., M. S. Lee, and N. Sarvetnick. 1994. Production of interleukin 10 by islet cells accelerates immune-mediated destruction of beta cells in nonobese diabetic mice. J. Exp. Med. 179:1379-1384.

35. Pennline, K. J., E. Roque-Gaffney, and M. Monahan. 1994. Recombinan human IL-10 prevents the onset of diabetes in the nonobese diabetic mouse. Immunol. Immunopathol. 71:169-175.

36. Rabinovitch, A., W. Sumoski, R. V. Rajotte, and G. L. Warnock. 1990. Cytotoxic effects of cytokines on human pancreatic islet cells in monolayer culture. J. Clin. Endocrinol. Metab. 71:151-156.

37. Foulis, A. K., M. McGill, and M. A. Farquharson. 1991. Insulitis in type I (insulin-dependent) diabetes mellitus in man-macrophages, lymphocytes, and interferon-gamma containing cells. J. Pathol. 165:97-103.

38. Campbell, I. L., A. Iscaro, and L. C. Harrison. 1988. IFN-gamma and tumor necrosis factor-alpha. Cytotoxicity to murine islets of Langerhans. J. Immunol. 141:2325-2329.

39. Sarvetnick, N., J. Shizuru, D. Liggitt, L. Martin, B. McIntyre, A. Gregory, T. Parslow, and T. Stewart. 1990. Loss of pancreatic islet tolerance induced by $\beta$-cell expression of interferon-gamma. Nature (Lond.). 346:844-847.

40. Campbell, I., T. W. H. Kay, L. Oxbrow, and L. C. Harrison. 1991. Essential role for interferon-gamma and interleukin-6 in autoimmune insulin-dependent diabetes in NOD/Wehi mice. J. Clin. Invest. 87:739-742. 